\title{
WAVE-LENGTH STANDARDS IN THE EXTREME ULTRA- VIOLET SPECTRA OF CARBON, NITROGEN, OXYGEN AND ALUMINUM
}

By I. S. Bowen and S. B. Ingram

\section{ABstract}

Wave-length determinations.-The wave-lengths of lines in the extreme ultra-violet spectra of carbon, nitrogen, oxygen and aluminum have been determined with an accuracy of .01 to $.04 \mathrm{~A}$ by direct comparison with iron standards.

$\mathrm{pp}^{\prime}$ groups in carbon $\mathrm{C}_{I I I}$ and nitrogen $\mathrm{N}_{\mathrm{IV}}-\mathrm{pp}^{\prime}$ Groups of carbon $\mathrm{C}_{\mathrm{III}}$ and nitrogen $\mathrm{N}_{\mathrm{IV}}$ have been completely resolved into six components and the ratio $p_{1} p_{2} / p_{2} p_{3}$ found to be 2.47 and 2.33 respectively.

\section{Determination of Wave-Lengths}

IN a preceding article by Dr. Millikan and one of the authors wavelength standards in oxygen and nitrogen were published. For these earlier determinations the strong aluminum lines between $1850 \mathrm{~A}$ and $2000 \mathrm{~A}$ served as primary standards. In the course of subsequent studies it has become increasingly evident that the wave-lengths of these aluminum lines were inconsistent with themselves, one of the doublet separations being in error by as much as $.17 \mathrm{~A}$. The present paper presents an attempt to eliminate this source of error by bringing high orders of strong lines in the extreme ultra-violet into direct comparison with first order iron lines. This standardization has also been carried to carbon and aluminum as well as to the nitrogen and oxygen reported in the ear.ier article, thus providing a set of standards completely covering the range from $600 \mathrm{~A}$ to $2000 \mathrm{~A}$.

For this purpose the spectrum of a vacuum spark between one aluminum and one iron electrode was photographed in various regions between $3000 \mathrm{~A}$ and $6000 \mathrm{~A}$. As has been noted previously such a spark brings out the carbon and oxygen lines strongly in addition to those of aluminum and iron.

In the determination of wave-lengths the first step was the calculation of approximate values on the assumption of a linear relationship between the position on the plate and the wave-length. Using these approximate values all iron lines appearing on the plate were identified and the difference between their true and approximate wave-lengths determined. Plotting these deviations against the wave-length gave a curve which

1 Bowen and Millikan, Phil. Mag. 48, 259 (1924). 
could be used in correcting the approximate wave-lengths of all other lines on the plate. In general this correction did not exceed one angstrom.

The various values of the wave-lengths of the oxygen, carbon, and aluminum lines were weighted as to order, sharpness of the line, and nearness to iron standards, and then averaged. As a further check on their mutual consistency and on the doublet separations the values thus determined were compared with the data obtained from a number of high order plates that had been taken for other purposes. Some slight adjustments were made to correct a few discrepancies brought to light by this comparison, but in no case was this adjustment greater than the indicated possible error in the wave-length (see below).

The best of the plates compared was that of a spectrum of a vacuum spark between aluminum electrodes containing sodium nitrate. The wave-lengths of the lines on this plate had previously been determined by means of a large number of first order oxygen lines occurring on it. The comparison with our carbon, oxygen, and aluminum standards indicated a systematic error of about $.04 \mathrm{~A}$ in this previous determination. After correcting for this small error the data from this plate were used for the determination of the nitrogen standards.

A test of the accuracy of the fine structure separations can be obtained by comparison of related series lines and $p p^{\prime}$ groups. Thus, an error of about $.01 \mathrm{~A}$ in any one of the four lines involved would account for the difference between the doublet separations of $1854 \mathrm{~A}$ and $1379 \mathrm{~A}$, and errors of from .006A to .009A would account for all discrepancies in the $p p^{\prime}$ groups at $685 \mathrm{~A}, 922 \mathrm{~A}$ and $1175 \mathrm{~A}$. It is also possible to check the absolute values of certain lines. Thus, the frequency of the 1935A line

TABLE I

\begin{tabular}{|c|c|c|c|c|c|c|c|}
\hline Int. & $\lambda$ I. A. Vac. & $\nu$ & Accuracy & Int. & $\lambda$ I. A. Vac. & $\nu$ & Accuracy \\
\hline \multicolumn{8}{|c|}{ Carbon } \\
\hline 5 & 977.031 & 102350.9 & $\mathrm{~B}$ & 2 & 1247.391 & 80167.3 & $\mathrm{C}$ \\
\hline 1 & 1009.863 & 99023.3 & B & 5 & 1334.541 & 74932.1 & B \\
\hline 1 & 1010.095 & 99000.6 & B & 5 & 1335.703 & 74866.9 & B \\
\hline 1 & 10 & 98972 & $B$ & 5 & 1548.189 & 64591 & \\
\hline 2 & 1036.339 & 96493.5 & A & 4 & 1550.774 & 64483.9 & A \\
\hline & 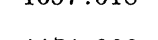 & 90450.0 & & 2 & 1560.257 & 64092.0 & B \\
\hline 3 & 1174.922 & 85112.0 & $\mathrm{~A}$ & 3 & 1560.660 & 64075.5 & $\mathrm{~B}$ \\
\hline 3 & 1175.261 & $\begin{array}{l}85087.5 \\
85064.6\end{array}$ & A & 3 & 1561.378 & 64046.0 & B \\
\hline 2 & 1175.577 & 85064.6 & A & & & & \\
\hline 4 & $\begin{array}{l}1175.711 \\
1175.988\end{array}$ & $\begin{array}{l}85054.9 \\
85034.9\end{array}$ & $\begin{array}{l}\mathrm{A} \\
\mathrm{B}\end{array}$ & 4 & 1931.027 & 51785.9 & B \\
\hline $\begin{array}{l}3 \\
3\end{array}$ & $\begin{array}{l}1175.988 \\
1176.359\end{array}$ & $\begin{array}{l}85034.9 \\
85008.1\end{array}$ & A & & & & \\
\hline
\end{tabular}


TABLE I (Continued)

\begin{tabular}{|c|c|c|c|c|c|c|c|}
\hline Int. & $\lambda$ I. A. Vac. & $\nu$ & Accuracy & Int. & $\lambda$ I. A. Vac. & $\nu$ & Accuracy. \\
\hline \multicolumn{8}{|c|}{ Nitrogen } \\
\hline 3 & 685.000 & 145985.4 & A & 4 & 989.802 & 101030.3 & B \\
\hline 3 & 685.517 & 145875.3 & A & 4 & 991.570 & 100850.2 & $\mathrm{~B}$ \\
\hline 4 & 685.822 & 145810.4 & A & & & & \\
\hline & 686.346 & 145699.1 & & $\begin{array}{l}5 \\
5\end{array}$ & $\begin{array}{l}1083.956 \\
1084.529\end{array}$ & $\begin{array}{l}92254.7 \\
92205.9\end{array}$ & $\begin{array}{l}\mathrm{B} \\
\mathrm{B}\end{array}$ \\
\hline 3 & 763.348 & 131001.8 & C & 3 & 1085.497 & 92123.7 & $\mathrm{C}$ \\
\hline 3 & 764.358 & 130828.7 & C & 6 & 1085.688 & 92107.5 & $\mathrm{C}$ \\
\hline 3 & 765.158 & 130692.0 & C & 2 & 1134.180 & 88169.4 & B \\
\hline 1 & 771.542 & 129610.6 & B & 3 & 1134.420 & 88150.8 & $\mathrm{~B}$ \\
\hline 2 & 771.914 & 129548.1 & B & 3 & 1134.987 & 88106.7 & $\mathrm{~B}$ \\
\hline 2 & 772.398 & 129466.9 & & & & & \\
\hline 1 & 772.938 & 129376.5 & C & $\begin{array}{l}3 \\
2\end{array}$ & $\begin{array}{l}1199.533 \\
1200.200\end{array}$ & $\begin{array}{l}83365.8 \\
83319.4\end{array}$ & $\begin{array}{l}\mathrm{B} \\
\mathrm{B}\end{array}$ \\
\hline 3 & 915.595 & 109218.6 & B & 1 & 1200.681 & 83286.1 & $\mathrm{C}$ \\
\hline 4 & 915.986 & 109172.0 & B & & & & \\
\hline 4 & 916.690 & 109088.1 & $\mathrm{~B}$ & 0 & 1740.315 & 57460.9 & $\stackrel{\mathrm{C}}{\mathrm{B}}$ \\
\hline 2 & 921.978 & 108462.5 & B & $\begin{array}{l}3 \\
3\end{array}$ & $\begin{array}{l}1742.740 \\
1745.260\end{array}$ & $\begin{array}{l}57380.9 \\
57298.1\end{array}$ & $\begin{array}{l}\mathrm{B} \\
\mathrm{B}\end{array}$ \\
\hline 2 & 922.512 & 108399.7 & B & 2 & 1747.855 & 57213.0 & $\mathrm{~B}$ \\
\hline 1 & 923.037 & 108338.0 & B & & & & \\
\hline 3 & 923.211 & 108317.6 & $B$ & & & & \\
\hline 2 & 923.658 & 108265.2 & B & & & & \\
\hline 2 & 924.264 & 108194.2 & $\mathrm{~B}$ & & & & \\
\hline \multirow[b]{2}{*}{2} & \multicolumn{4}{|c|}{ Oxygen } & \multirow{10}{*}{$\begin{array}{l}796.665 \\
\\
832.754 \\
832.924 \\
833.327 \\
833.739 \\
834.459 \\
835.099 \\
835.288\end{array}$} & \multirow{10}{*}{$\begin{array}{l}125523.3 \\
120083.5 \\
120059.0 \\
120000.9 \\
119941.6 \\
119838.1 \\
119746.3 \\
119719.2\end{array}$} & \multirow{10}{*}{$\begin{array}{l}\text { B } \\
\text { A } \\
\text { A } \\
\text { A } \\
\text { A } \\
\text { A } \\
\text { A } \\
\text { A }\end{array}$} \\
\hline & 599.600 & 166777.9 & $\mathrm{~B}$ & 2 & & & \\
\hline 2 & 702.329 & 142383.4 & A & 4 & & & \\
\hline 2 & 702.813 & 142285.4 & A & 3 & & & \\
\hline 2 & 702.905 & 142266.7 & A & 4 & & & \\
\hline 3 & 703.850 & 142075.7 & A & 4 & & & \\
\hline 3 & 718.522 & 139174.6 & B & $\begin{array}{l}5 \\
3\end{array}$ & & & \\
\hline & & & & 5 & & & \\
\hline 1 & 779.824 & 128234.1 & B & & & & \\
\hline $\begin{array}{l}2 \\
2\end{array}$ & $\begin{array}{l}787.716 \\
790.205\end{array}$ & $\begin{array}{l}126949.3 \\
126549.4\end{array}$ & $\begin{array}{l}\mathrm{B} \\
\mathrm{B}\end{array}$ & & & & \\
\hline \multicolumn{8}{|c|}{ Aluminum } \\
\hline 2 & 1352.857 & 73917.6 & A & 4 & 1760.101 & 56814.9 & A \\
\hline & 1379.675 & 72480.8 & $B$ & 4 & 1761.973 & $\begin{array}{l}56754.6 \\
566913\end{array}$ & A \\
\hline $\begin{array}{l}7 \\
4\end{array}$ & 1384.140 & 72247.0 & B & 4 & 1765.814 & 56631.1 & $\begin{array}{l}\text { A } \\
\text { A }\end{array}$ \\
\hline & & & & 4 & 1767.730 & 56569.7 & A \\
\hline 7 & 1605.764 & 62275.7 & B & & & & \\
\hline 7 & 1611.858 & 62040.2 & B & 10 & 1854.715 & 53916.6 & $\mathrm{~B}$ \\
\hline 6 & 1670.802 & 59851.5 & C & & & & \\
\hline & & & & 6 & 1935.881 & 51656.1 & B \\
\hline 5 & 1721.273 & 58096.5 & A & 4 & 1990.534 & 50237.8 & B \\
\hline 5 & 1724.982 & 57971.6 & A & & & & \\
\hline
\end{tabular}


and the difference in the frequencies of the lines at $1605 \mathrm{~A}$ and $1379 \mathrm{~A}$ can be calculated from series relationships. In both of these cases the error does not exceed .003A.

The intensities and final wave-lengths are given in the first two columns of Table I. A letter $A$ in the fourth column indicates that the line can probably be depended upon to $.01 \mathrm{~A}, B$ indicates $.02 \mathrm{~A}$, and $C .03 \mathrm{~A}$ or $.04 \mathrm{~A}$.

\section{The $p p^{\prime}$ Groups in Carbon $\mathrm{C}_{\text {III }}$ and Nitrogen $\mathrm{N}_{\mathrm{IV}}$}

Among the lines studied in the above work were the $p p^{\prime}$ groups of carbon $\mathrm{C}_{I I I}$ and nitrogen $\mathrm{N}_{\mathrm{IV}}$ which were here for the first time completely resolved into their six components as shown in Table II. This enables us to determine the ratios of the separations of $p_{1} p_{2}$ and $p_{2} p_{3}$ which are given in Table III together with all previous determinations in related

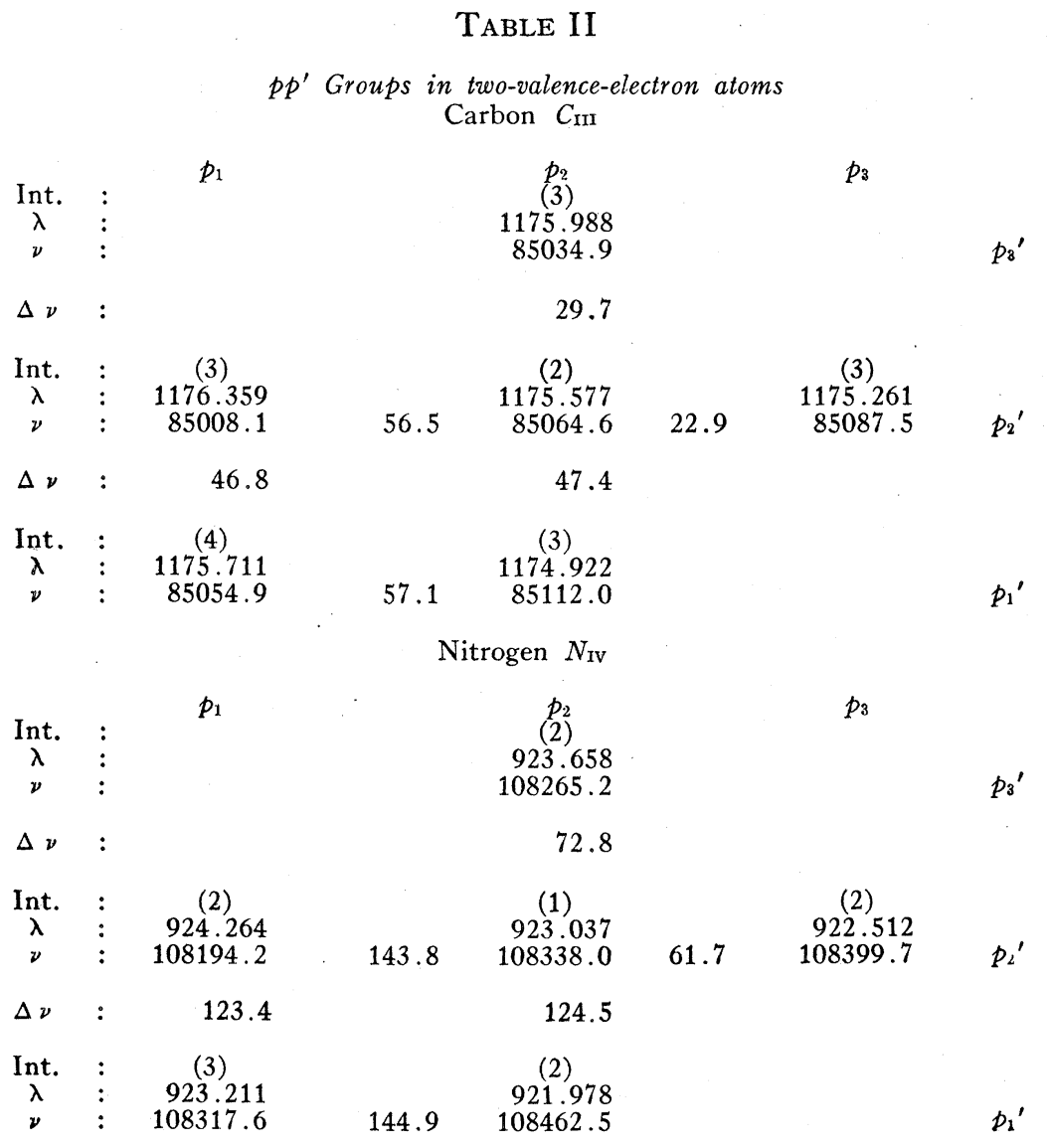




\section{TABLE III}

$\begin{array}{ccc}\text { Ratio of the triplet separations } & p_{1} p_{2} / p_{2} p_{3} \\ & 2 p & 3 p \\ \mathrm{Be}_{\mathrm{II}} & 3.57 & \\ \mathrm{~B}_{\mathrm{II}} & 2.47 & 2.33 \\ \mathrm{C}_{\mathrm{III}} & 2.33 & \\ \mathrm{~N}_{I V} & 2.27 & \\ \mathrm{O}_{\mathrm{V}} & \end{array}$

elements. It is at once seen that in going to elements of higher atomic number this ratio approaches the value 2 called for by Landé's interval rule.

Norman Bridge Laboratory of Physics,

California Institute of Technology,

Pasadena, California.

June 8, 1926. 